\title{
Successive Uveal Melanomas with Different Gene Expression Profiles in an Eye with Ocular Melanocytosis
}

\author{
Tanya Glaser Akshay S. Thomas Miguel A. Materin \\ Department of Ophthalmology, Duke University, Durham, NC, USA
}

\section{Established Facts}

- Ocular melanocytosis is associated with increased risk of uveal melanoma.

- Multifocal uveal melanoma is rare and tumors can differ in the histopathology and genetics.

\section{Novel Insights}

- Uveal melanoma-specific gene expression profile testing could be useful to differentiate between two primary tumors and offers prognostic information which can alter management.

\section{Keywords}

Uveal melanoma · Ocular melanocytosis · Gene expression profile · Plaque brachytherapy

\begin{abstract}
Ocular melanocytosis portends a higher risk of uveal melanoma. Multifocal uveal melanoma has been described previously and has been associated with ocular melanocytosis. Historically, histopathology has been used to differentiate tumors; however, molecular profiling now allows for better prognostication and determination of metastatic risk. The present case describes a patient with ocular melanocytosis who developed two sequential uveal melanomas in the same eye separated by 4 years. The uveal melanoma-specific gene expression profile (GEP) testing for the first tumor
\end{abstract}

\section{KARGER}

(c) 2018 S. Karger AG, Basel

E-Mail karger@karger.com

www.karger.com/oop was class $1 \mathrm{~A}$ and the second tumor was class 2 . While the first tumor had low metastatic risk, the second tumor had a higher risk of metastasis, demonstrating the importance of GEP testing in cases of multifocal disease.

(ㄷ) 2018 S. Karger AG, Basel

\section{Introduction}

Ocular melanocytosis portends a higher risk of uveal melanoma [1]. Multifocal uveal melanoma has been described previously and has been associated with ocular melanocytosis [2-4]. Historically, histopathology has been used to differentiate and classify tumors; however, genotyping now allows for prognostication and determination of metastatic risk $[5,6]$. The uveal melanoma-spe- 

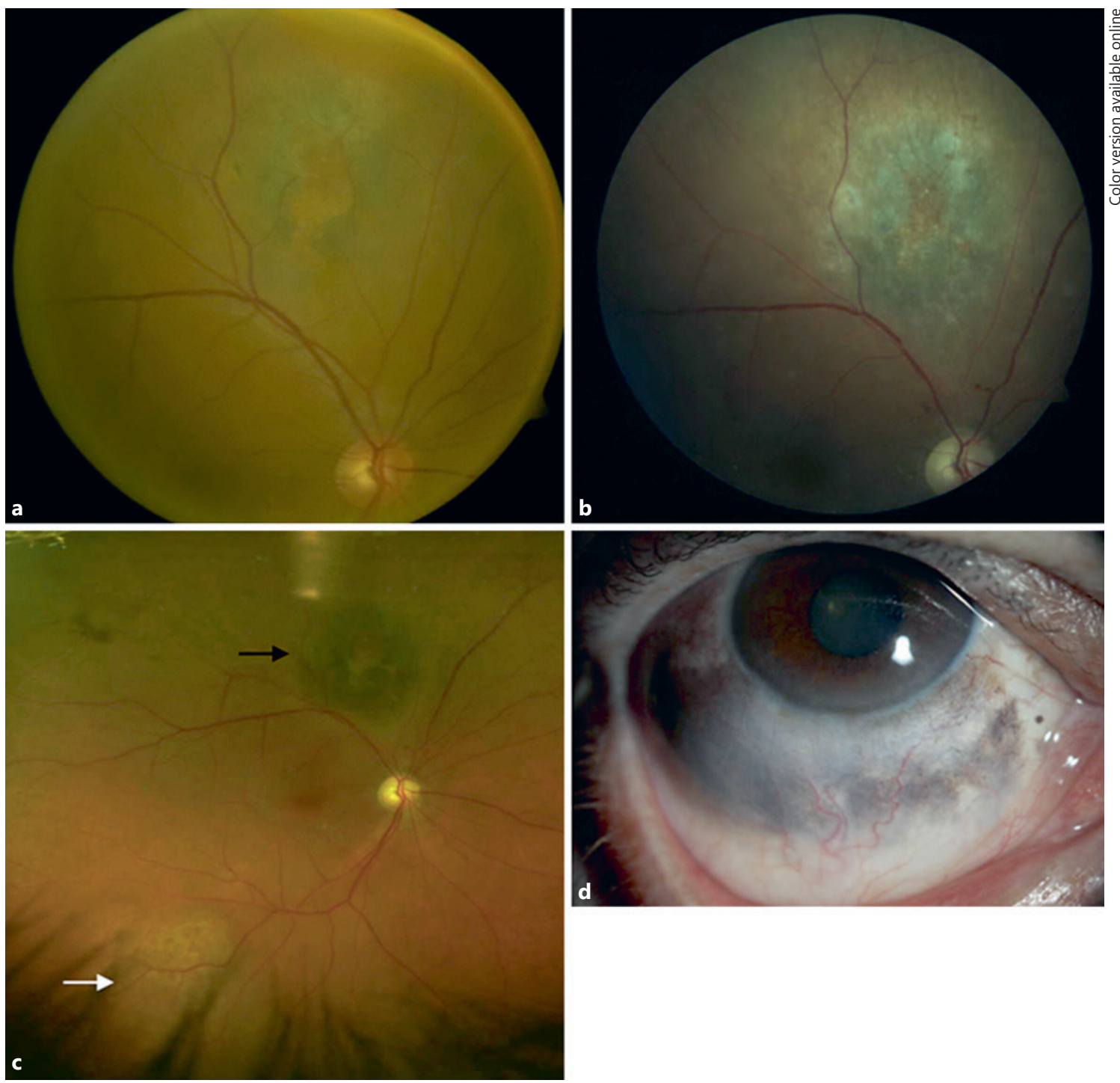

Fig. 1. First tumor located superior to the optic nerve, before treatment (a) and after treatment (b). c Wide view showing the first (treated) tumor superior to the optic nerve (black arrow) and the second tumor along the distal inferotemporal arcade at diagnosis (white arrow). $\mathbf{d}$ External photo demonstrating episcleral pigmentation typical of ocular melanocytosis.

cific gene expression profile (GEP) separates tumors into class 1 and class 2 tumors based on the results of a panel of 15 genes. Class $1 \mathrm{~A}$ tumors have a $2 \% 5$-year metastatic risk, while class $1 \mathrm{~B}$ tumors have a $21 \% 5$-year metastatic risk. Class 2 tumors have a $72 \% 5$-year metastatic risk and are associated with high-risk clinical tumor features and genetic features such as monosomy 3 , which are independent predictors of metastatic disease $[5,6]$. The following case describes a patient with ocular melanocytosis who developed two sequential uveal melanomas that were found to be two different GEP tumor classes.

Successive Uveal Melanomas with Different GEPs

\section{Case Report}

A 53-year-old Caucasian male was found to have an asymptomatic choroidal tumor in the right eye (OD) on routine exam. He denied a personal or family history of cancer. On exam, bestcorrected visually acuity was 20/25 OD and 20/20 in the left eye (OS). Exam was notable for pigment in the angle, patchy blue-grey episcleral pigmentation, and a pigmented choroidal lesion located $3.0 \mathrm{~mm}$ superior to the optic nerve (Fig. 1), measuring $6.6 \times 6.5 \times$ $3.0 \mathrm{~mm}$ with overlying lipofuscin and associated subretinal fluid. A CT of the chest and abdomen was negative for metastasis. Two weeks later, the patient underwent fine needle aspirate (FNA) biopsy of the lesion and iodine-125 plaque brachytherapy. The bi- 

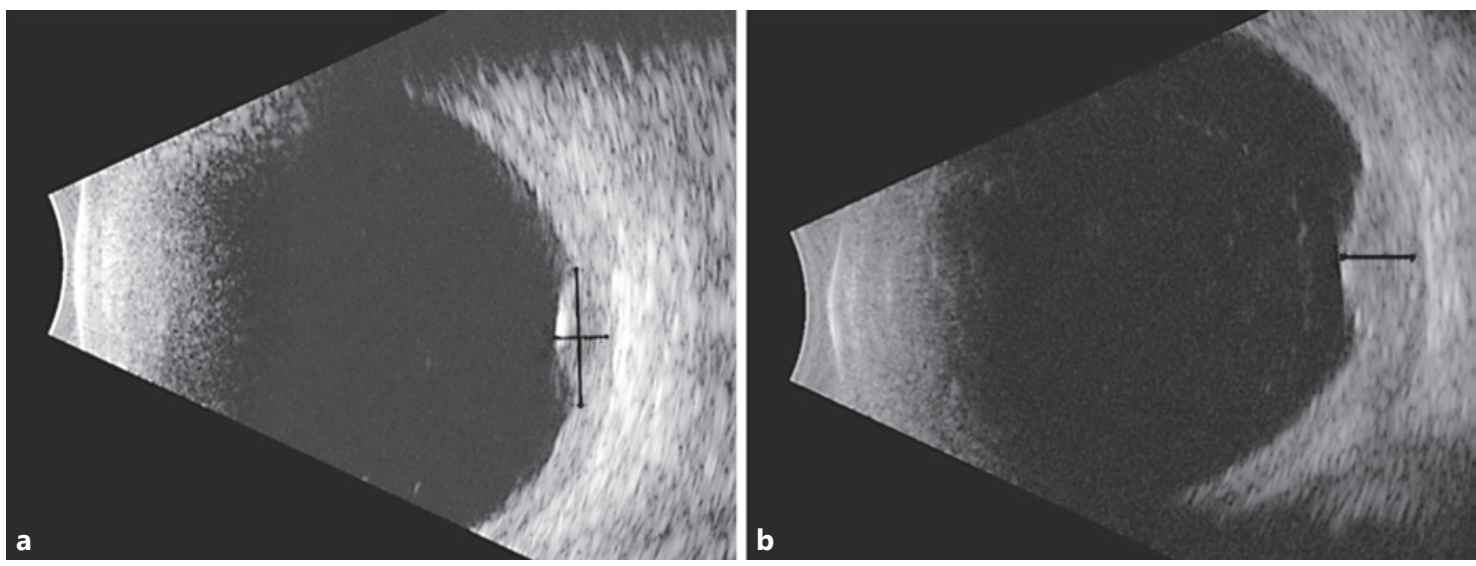

Fig. 2. B-scan ultrasound at time of diagnosis of second tumor. First tumor with stable tumor thickness (a) and second tumor measuring $10.0 \times 10.0 \times 3.5 \mathrm{~mm}(\mathbf{b})$.

opsy sample was sent to Castle Biosciences Incorporated (Phoenix, AZ, USA) for uveal melanoma-specific GEP testing for molecular prognostication. The DecisionDx ${ }^{\circledR}$-UMGenetic testing identified this tumor as a class $1 \mathrm{~A}$ tumor. Follow-up studies showed a good response to treatment with atrophy of the tumor and subsequently stable size over visits. The patient developed secondary radiation retinopathy and a superior branch retinal vein occlusion, which were treated with posterior sub-Tenon's triamcinolone injections, bevacizumab intravitreal injections, and focal laser. He was followed on average four times per year without evidence of recurrence on exam.

On routine follow-up 4 years after the initial presentation, a second asymptomatic elevated pigmented choroidal lesion was identified along the distal inferotemporal arcade of the right eye (Fig. 1). Best-corrected visually acuity was stable at 20/320. On ultrasound, the previously treated uveal melanoma appeared stable and the new tumor measured $10.0 \times 10.0 \times 3.5 \mathrm{~mm}$ (Fig. 2). The tumor had overlying lipofuscin and associated subretinal fluid. Treatment options, including enucleation or placement of a second plaque, were discussed with the patient. Systemic testing was negative for metastasis. The patient subsequently underwent FNA biopsy of the new lesion and placement of an iodine-125 radioactive plaque. The biopsy sample was sent for GEP testing, which identified the new lesion as a class 2 tumor.

\section{Discussion}

Uveal melanoma is the most common primary malignant intraocular tumor in adults [7] and the incidence of uveal melanoma is highest among Caucasians [8]. While uncommon, the findings of bilateral uveal melanomas [9-14] and multiple primary uveal melanomas in the same eye have been reported [2-4]. The congenital condition ocular melanocytosis, which is characterized by me- lanocytic hyperpigmentation of the episclera and uvea, has been associated with a 1 in 400 lifetime risk of developing uveal melanoma [1]. Patients with ocular melanocytosis, when compared to the general population, also have an increased risk of developing two isolated tumors in a single eye [2]. This was the case for our patient, who was noted to have diffuse unilateral grey-blue pigmentation of the episclera with the development of two distinct uveal melanomas separated by a period of 4 years.

Previously reported cases of multifocal unilateral ocular melanoma have relied on histopathological features to identify and differentiate tumors. Histopathological features alone can make it difficult to distinguish multiple de novo tumors from diffuse choroidal melanoma with multinodular, multifocal choroidal metastases or local recurrence of previously treated melanomas. More recently, genetic analysis has been used to further differentiate multiple uveal melanomas when they are localized to the same eye $[3,13]$.

Our case is the first to use uveal melanoma-specific GEP testing on two primary uveal melanomas from the same eye. In our patient, genetic prognostic testing revealed the first tumor to be a class $1 \mathrm{~A}$ and the second tumor to be a class 2 tumor. This suggests two separate de novo uveal melanomas, the first with low risk and the second with high risk of metastasis. This case demonstrates the importance of obtaining biopsies when there is concern for local recurrence or for a second primary tumor as the genetics and prognosis can differ. One caveat to these findings is that the FNA biopsy specimen was sent for GEP testing and molecular prognostication only and cytopathology was not performed. Without pa- 
thology of the globe we cannot definitively address whether this is a primary melanoma with persistent growth after treatment, a diffuse extension, or a second primary tumor. However, tumor locations, excellent first tumor response, close follow-up with rapid growth of second tumor, underlying ocular melanocytosis, and different GEP type all suggest a second primary tumor. Despite this drawback, the genetic testing for our patient proved critical for prognostication and will dictate the frequency and intensity of his follow-up and surveillance imaging going forward.

\section{Statement of Ethics}

All work presented here complies with the guidelines for human studies and animal welfare regulations. The review of medical records for publication of a single case report or a case series involving data from two or three patients is not considered by the Duke University Health System IRB to be research involving human subjects, and therefore such a report of medical cases does not require IRB review and approval.

\section{Disclosure Statement}

Miguel A. Materin, MD is a consultant for Castle Biosciences. None of the other authors on this paper have any conflicts of interest, sponsorship, or funding arrangements related to the case presented in the paper.

\section{References}

1 Singh AD, De Potter P, Fijal BA, Shields CL, Shields JA, Elston RC: Lifetime prevalence of uveal melanoma in white patients with oculo(dermal) melanocytosis. Ophthalmology $1998 ; 105: 195-198$.

2 Honavar SG, Shields CL, Singh AD, et al: Two discrete choroidal melanomas in an eye with ocular melanocytosis. Surv Ophthalmol 2002; 47:36-41.

3 Nissen EJ, Kalirai H, Damato B, Heimann H, Coupland SE: Two distinct uveal melanomas in the same eye. JAMA Ophthalmol 2015;133: 1094-1096.

4 Shields CL, Eagle RC, Ip MS, Marr BP, Shields JA: Two discrete uveal melanomas in a child with ocular melanocytosis. Retina 2006;26: 684-687.

5 Harbour JW: A prognostic test to predict the risk of metastasis in uveal melanoma based on a 15-gene expression profile. Methods Mol Biol 2014;1102:427-440.
6 Onken MD, Worley LA, Char DH, et al: Collaborative Ocular Oncology Group report number 1: prospective validation of a multigene prognostic assay in uveal melanoma. Ophthalmology 2012;119:1596-1603.

7 Wilkes SR, Robertson DM, Kurland LT, Campbell RJ: Incidence of uveal malignant melanoma in the resident population of Rochester and Olmsted County, Minnesota. Am J Ophthalmol 1979;87:639-641.

8 Hu DN, Yu GP, McCormick SA, Schneider S, Finger PT: Population-based incidence of uveal melanoma in various races and ethnic groups. Am J Ophthalmol 2005;140:612-617.

9 Eide N, Garred O, Beiske K, Fodstad O: Bilateral uveal melanomas with different gene expression detected with 7 years interval. Acta Ophthalmol 2016;94:99-102.
10 Furuta M, Shields CL, Uysal Y, Shields JA: Bilateral primary choroidal melanoma treated with bilateral plaque radiotherapy: a report of three cases. Eur J Ophthalmol 2006;16:879882 .

11 Hadden PW, Damato BE, McKay IC: Bilateral uveal melanoma: a series of four cases. Eye (Lond) 2003;17:613-616.

12 Lois N, Shields CL, Shields JA, De Potter P, Ramsey MS: Trifocal uveal melanoma. Am J Ophthalmol 1997;124:848-850.

13 Tappin MJ, Parsons MA, Sisley K, Rees RC, Rennie IG: Two cases of double melanoma of the uvea. Eye (Lond) 1996;10(Pt 5):600-602.

14 Cordes FC, Cook RD: Simultaneous bilateral primary ocular malignant melanoma; report of a case. Trans Am Ophthalmol Soc 1949;47: 80-92. 